\title{
Endocrine and metabolic disorders in HTLV-1 infected patients
}

\begin{abstract}
Human T-cell leukemia virus type 1 (HTLV-1) infection is endemic in Japan and several countries in South America, Caribbean and Africa. Endocrine and metabolic disorders have been variably reported to be associated with human T-cell leukemia virus type 1 (HTLV-1) infection. Therefore, the aim of this article was to critically evaluate the current knowledge of the endocrine and metabolic disorders associated with HTLV-1 infection. The literature search used PubMed, Web of Science, and LILACS databases in the past 10 years, utilizing, in various combinations, the following keywords: HTLV-1, adult T-cell leukemia, diabetes mellitus, GLUT-1, osteoporosis, hypercalcemia, autoimmune thyroid disorders, diabetes insipidus, inappropriate antidiuretic hormone secretion; pseudohypoparathyroidism; pseudopseudohypoparathyroidism. The proven endocrine manifestations of the HTLV-1 infection are calcium disorders which occur in some patients with acute HTLV-1/Adult T-cell leukemia/lymphoma. The few reports about thyroid, parathyroid, antidiuretic hormone and diabetes mellitus are insufficient to prove a causal association with HTLV-1 infection. The evidence for an association between endocrine disorders and HTLV-1 infection in general, and in asymptomatic patients is lacking. Given all these uncertainties, the endocrine expression of the HTLV-1 infection composes a promising research line for understanding the pathophysiology of this infection.
\end{abstract}

Keywords: HTLV-1; adult T-cell leukemia; endocrine disorders; metabolic disorders.

[Braz J Infect Dis 2010;14(6):613-620]@Elsevier Editora Ltda.
Authors

Cresio Alves ${ }^{1}$

Luciano Dourado

${ }^{1} \mathrm{MD}, \mathrm{PhD}$ - Chief of Pediatric Endocrinology, Hospital Universitário Prof. Edgard Santos, Faculty of Medicine, Universidade Federal da Bahia.

${ }^{2} \mathrm{MD}$ - Fellow in Pediatric Endocrinology, Pediatric Endocrinology Service, Hospital Universitário Professor Edgard Santos, Faculty of Medicine, Universidade Federal da Bahia.

\section{INTRODUCTION}

The human T-cell lymphotropic virus (HTLV) is a retrovirus classified into four types: HTLV-1, 2, 3 and $4 .{ }^{1,2}$ Despite that $95 \%$ of the HTLV-1 infected individuals remain asymptomatic, this infection can cause syndromes such as adult T-cell leukemia/lymphoma (ATLL), HTLV-1-associated myelopathy/tropical spastic paraparesis (HAM/TSP), polymyositis, arthritis and infective dermatitis. ${ }^{1-3}$

The HTLV-1 infection is endemic in Japan and several countries in South America, Caribbean and Africa., ${ }^{2,-7}$ The transmission pathways of HTLV-1 infection include vertical, parenteral and sexual transmission. ${ }^{2,7}$ Risk factors associated with HTLV-1 infection include: hemotransfusion, low socioeconomic status, low education level, high-risk sexual behavior, anal sex, first sexual relationship before 18 year-old and having more than 3 sexual partners in life. ${ }^{7,8}$
Several studies have been evidencing association between HTLV-1 infection and endocrinopathies and other metabolic disorders such as autoimmune thyroid diseases, hypercalcemia, type 1 diabetes mellitus and pseudohypoparathyroidism. ${ }^{1,9-12}$ Due to the importance of these disturbances in the clinical spectrum of the HTLV-1 infection, this study aims to review the current knowledge about the endocrine diseases related to the HTLV-1 infection.

\section{ENDOCRINE-METABOLIC DISORDERS ASSOCIATED WITH HTLV-1 INFECTION}

\section{CALCIUM DISORDERS}

\section{Hypercalcemia and osteoporosis}

Adult T-cell leukemia/lymphoma (ATLL) associated with the HTLV-1 infection is a neoplasia with an average survival of six months in the
Submitted on: 03/10/2010 Approved on: 04/28/2010

Correspondence to: Cresio Alves, MD, PhD Pediatric Endocrinology Service, Hospital Universitário Professor Edgard Santos, Faculty of Medicine, Universidade Federal da Bahia Rua Plinio Moscoso 222/601, 40157-190, Salvador, Bahia, Brazil E-mail: cresio.alves@uol. com.br

We declare no conflict of interest 
acute form. ${ }^{13-15}$ It affects $5 \%$ of the patients, starting in the average age of 58 years-old. ${ }^{16-17}$ In $70 \%-80 \%$ of the acute ATLL form, the patients develop the humoral hypercalcemia of malignancy (HHM), a paraneoplastic syndrome characterized by hypercalcemia, osteoporosis and osteolytic lesions. ${ }^{13-15,18,19}$ This suggests that there should be released or expressed molecules in ATLL cells performing a crucial role in HHM etiology. ${ }^{20}$

The HHM of patients with acute ATLL is caused by mechanisms that act synergistically, affecting directly or indirectly the osteoclastic differentiation. The most studied mechanisms are: (I) receptor activator of the nuclear factor-kB ligand (RANKL); (II) osteoprotegerin (OPG); (III) parathyroid hormone-related protein (PTHrP); (IV) pro-inflammatory cytokines; $(\mathrm{V})$ macrophage inflammatory protein-1 alpha (MIP-1 alpha); (VI) nonstructural viral protein Tax; (VII) viral envelope protein, Gp-4; and (VIII) metalloproteinases.

\section{RANKL}

RANKL (receptor activator of the nuclear factor-kB ligand) is a surface protein, part of the superfamily of TNF (tumoral necrosis factor), which when bound to their receptors (RANK) expressed in the osteoclastic precursors stimulates its differentiation in mature osteoclast, increasing its bone resorption and causing hypercalcemia and osteoporosis. ${ }^{21}$ Patients with ATLL and hypercalcemia present increase of the expression of RANK. ${ }^{14,18}$ Thus, the invasion of the bone marrow by ATLL cells expressing RANKL in its surface induces osteoclastic differentiation causing hypercalcemia.

\section{Osteoprotegerin}

Osteoprotegerin (OPG) is a soluble receptor from the family of the tumoral necrosis factor (TNF) produced by several types of cells, including osteoblasts. It acts as a decoy receptor by binding and neutralizing RANK and its effect in the differentiation and proliferation of the osteoclasts. ${ }^{22}$ Studies in vitro have shown that OPG inhibits the osteoclastogenesis, blocking the bone resorption by mature osteoclast and promoting osteoclastic apoptosis. ${ }^{14}$ Mice with increased expression of OPG are osteopetrotic ${ }^{23}$ while animals with deficiency of OPG present osteoporosis. ${ }^{24}$ Nosaka et al. suggest that the decrease in the production of OPG in patients with ATTL can be one of the pathogenic mechanisms of the hypercalcemia. ${ }^{18}$

\section{PTHrp}

The PTHrP (parathyroid hormone-related protein) is a peptide that binds to PTH1R (parathyroid hormone-1 receptors) promoting osteoclastic resorption, suppression of the osteoclastic activity and increase in the calcium urinary resorption. Patients infected by HTLV-1 present elevation of the PTHrP levels, mainly those with ATLL and HAM-TSP. ${ }^{1}$ Fukumoto et al. evidenced hy- percalciuria and increase of urinary excretion of cyclic AMP in 10 patients with ATLL, suggesting that the hypercalcemia was caused by the chronic increased mobilization of calcium. ${ }^{25}$ Studies of cellular lineages infected by HTLV-1 have disclosed the production of a factor that stimulated the activity of the adenylyl cyclase in osteoblastic membranes, being the mRNA (messenger RNA) from these cells homologous to the mRNA of the PTHrP gene. ${ }^{26,27}$ A study with ATLL patients, normo or hypercalcemic, has revealed that a rise in the expression of the PTHrP gene is directly proportional to the population of leukemic cells. ${ }^{28}$ The trans-activation of the promoter of PTHrP by the protein Tax from HTLV-1 virus seems to be one of the mechanisms of expression of the PTHrP gene in the infected cells. ${ }^{28}$ The PTHrP also boost the production of pro-inflammatory cytokines, stimulating the synthesis of interleukin 6 (IL-6) by osteoblasts and IL- 8 and TNF-alpha by non-osseous tissues, for example the immune system. ${ }^{20}$ Although the PTHrP and its receptors are upregulated in the ATLL, HAM/TSP and asymptomatic carriers of HTLV-1, other host factors are necessary for an accentuated expression of this peptide. ${ }^{17}$ As the PTHrP is not able to induce the differentiation of the precursor hematopoietic cells into osteoclasts and an association between their elevated serum levels and HHM is not always observed, this indicates that other mechanisms contribute to this process. ${ }^{18}$

\section{Pro-inflammatory cytokines}

The interleukin 2 (IL-2) stimulates the production and secretion of PTHrP and the IL-5 acts synergistically with PTHrP in the development of hypercalcemia. ${ }^{29}$ Other cytokines as TGF-beta (transforming growth factor-beta), TNF-alpha and IL-1 also increment the expression of PTHrP in a variety of tissues. ${ }^{29}$ As some patients present hypercalcemia without cytokine elevation, it is implicit the participation of other mechanisms. ${ }^{30}$

\section{MIP-1alpha}

The MIP-1alpha (macrophage inflammatory protein-1alpha) is a chemokine that acts as a stimulating factor for osteoclasts and monocyte migration (precursors of osteoclasts), besides inducing the expression of RANKL in ATLL. Okada et al., studying 24 patients with ATLL and hypercalcemia, found high levels of MIP-1alpha in all patients, comparing to the positive finding in only $3 / 37$ patients with ATLL without hypercalcemia. ${ }^{30}$ After chemotherapy, the decrease in the serum levels of calcium had a concomitant decrease in MIP-1alpha levels, supporting the role of this protein in the pathogenesis of hypercalcemia. Besides, osteoprotegerin and anti-MIP-1alpha antibodies inhibited the transformation of peripheral mononuclear cells into osteoclasts. ${ }^{30}$ 


\section{Viral tax protein}

The nonstructural viral protein tax is able to activate CREB (cellular transcription factor CRE-binding protein), which renders activation of RANKL by PTHrP, resulting in hypercalcemia. ${ }^{31}$ The role of Tax in the pathogenesis of hypercalcemia in the ATLL is controversial. Studies in vivo with mice have not exposed accretion in the expression of Tax in these animals, suggesting that other factors influence the regulation of PTHrP. ${ }^{29}$ On the other hand, Gao et al. have shown that Tax transgenic (Tax + ) mice develop hypercalcemia, osteolytic lesions and increased osteolytic activity whose expression was attenuated by use of drug inhibitors of osteoclasts. ${ }^{32}$

\section{Viral gp46-197 protein}

Sagara et al. depicted that rabbits immunized with a HTLV-1 structural protein (gp46-197) died due to hypercalcemia after receiving a boost of this peptide. ${ }^{14}$ They suggest that gp46-197 would be an antigen mimicry of the osteoprotegerin, blocking its action by sharing the same antigenic sites. ${ }^{14}$ The infusion of gp46-197 in mice resulted in a decrease in bone growth and hypercalcemia, which was curbed by the concurrent use of osteoprotegerin. ${ }^{14}$

\section{Matrix metalloproteinases}

The matrix metalloproteinases (MMPs) are enzymes that act in the extracellular matrix contributing to the formation and remodeling of bones and cartilages. ${ }^{1,33}$ Mice deficient in a type of MMPs (MT1-MMP) present severe defects in the development of the axial and appendicular skeleton and craniofacial alterations as a consequence of the decrease of the proliferation of chondrocytes in the growth plate. ${ }^{33} \mathrm{Sch}-$ achter et al. proposed that an infection by the HTLV-1 could deregulate extracellular matrix proteins and its tissue inhibitors leading to the development of osteoporosis in patients with HAM/TSP. ${ }^{1}$

\section{PSEUDOHYPOPARATHYROIDISM AND PSEUDOPSEUDOHYPOPARATHYROIDISM}

Pseudohypoparathyroidism (PHP) is a term used to define a group of disorders characterized by resistance to the peripheral action of the parathyroid hormone (PTH). PHP is classified into IA (classical presentation), IB, IC, II and pseudopseudohypoparathyroidism. ${ }^{34}$ Only three papers, indexed in MEDLINE, reporting the association between HTLV-1 and PHP, were published. The first depicted three cases of PHP in patients with juvenile onset of HAM/TSP. ${ }^{35}$ Although all presented hypocalcemia, none of them had hyperphosphatemia. PTH was elevated in only one patient; none of them demonstrated increase of the phosphorus urinary concentration or cyclic AMP in response to the exogenous administration of PTH. In the second article, an additional 11 patients were depicted. ${ }^{12}$ In this study, only half of the patients had hypocalcemia, one had hyperphosphatemia and another, elevated PTH. The serum levels of $1,25(\mathrm{OH})_{2}$ vitamin D were tested in three of seven patients. There was no report informing if those who had normal levels of vitamin D have been subject to reposition of this vitamin. The third article portrayed a patient with HAM/ TSP and PPHP, without elevation of PTH. ${ }^{36}$ What the patients in these articles had in common was a decline in the activity of Gs $\alpha$ in the membrane of erythrocytes and renal resistance to $\mathrm{PTH}$, which is not enough to establish a diagnosis of PHP or PPH. ${ }^{37}$

The authors of these articles postulate that a possible mechanism for juvenile onset HAM/TSP is a state of immunodeficiency caused by deficiency of $1,25(\mathrm{OH})_{2}$ vitamin D as a result of PHP. ${ }^{35}$ Besides, they report that the HTLV-1 infection is not an inductor factor for PHP, but that PHP is a risk factor for a precocious onset of HAM/TSP in patients infected through blood transfusion, explaining this way the more precocious onset of HAM/TSP in these patients..$^{12,36}$

\section{THYROID DISORDERS}

\section{Autoimmune thyroid diseases}

Hashimoto's thyroiditis (HT) and Graves' disease (GD) are diseases characterized by humoral and cellular autoimmunity. ${ }^{38,39}$ The retrovirus, being able to integrate in the cellular genome, can participate in the development of autoimmune disease, either through the expression of foreign antigens through alteration of expression of autoantigen or through the unbalance of subpopulations of serum lymphocytes. ${ }^{40-42}$ Some evidences relate HTLV-1 infection as a possible pathogenic factor in the autoimmune thyroid diseases.

\section{Higher prevalence of seropositivity for HTLV-1 in patients with HT}

Kawai et al., studying 144 patients with HT, found a higher frequency of seropositivity for HTLV- $1 .{ }^{43}$ In the same study, 33.3\% of the HAM/TSP patients had evidence of HT, comparing with a $1.7 \%$ prevalence in the same region. Mizokami et al. found a higher HTLV-1 seropositive prevalence in individuals with HT and positive antithyroid antibodies. ${ }^{44}$ Mine et al., studying 1,019 blood donors found a stronger association between HTLV-I seropositivity and the presence of antithyroid antibodies, when compared with seronegative controls. ${ }^{45}$ Akamine et al. demonstrated a high prevalence of antithyroid antibodies in carriers of the virus and ATLL patients. ${ }^{10}$ Lagaye et al., studying patients with polyendocrinopathies, did not detect HTLV-1 antibodies through ELISA and Western Blot; but when Southern Blot and PCR methods were used, the viral DNA was detected in $35 \%$ of the patients. ${ }^{42}$ Concerning to GD, Smikle et al. found a $6 \% \mathrm{HTLV}-1$ positivity for GD patients, comparing to a $4 \%$ seropositivity in healthy controls, which does not favor the association between HTLV-1 infection and GD. ${ }^{11}$ 


\section{Detection of viral products in the follicular cells of patients with autoimmune thyroidopathy}

Kawai et al. found HTLV-1 viral proteins in thyroid tissue in HTLV-1 and TH patients ${ }^{46}$ and, in another study, they detected the HTLV-1 viral protein gp46 in thyroid follicular cells indicating previous thyroid tissue viral infection and probable association between these two diseases. ${ }^{47}$ Filho et al., studying thyroid tissue from cadavers with GD and HT and normal controls, found $83 \%$ and $85 \%$ positivity for p19(gag) and gp21(env) HTLV-1 proteins, respectively, without any clinical evidence of HTLV-1 infection. ${ }^{48}$ These findings did not confirm the role of HTLV-1 in the pathogenesis of thyroid autoimmunity, but suggest that they can be the result of cross reaction, molecular mimicry or endogenous retrovirosis.

\section{Detection of a higher viral load of HTLV-1 in patients with autoimmune thyroid diseases}

Matsuda et al. found a higher HTLV-1 proviral load in the peripheral blood of patients with HT and GD comparing to asymptomatic carriers of the virus. ${ }^{49}$ In this study there was no association between the proviral load and the titles of antithyroid antibodies. As the proviral load is a determinant factor for the development of the virus clinical manifestations it is possible that it takes part in the pathogenesis of autoimmune thyroid disease in HTLV-1 infected patients.

\section{Association between HTLV-1 infection and CTLA-4 polymorphisms}

The CTLA-4 (cytotoxic T-lymphocyte antigen-4) is a molecule that decreases the immune response of T-cells, being implicated in the pathogenesis of autoimmune thyroid diseases. ${ }^{50}$ Thus, polymorphisms of this gene could be associated with a higher positivity to thyroid diseases in HTLV-1 infected patients. Nevertheless, Tomoyose et al. did not find difference in the frequency of this polymorphism in patients with TH with or without positive HTLV-1 test, concluding that HTLV-1 infection is not regulated by CTLA-4. ${ }^{51}$

\section{Reports of autoimmune systemic manifestation of HTLV-1 associated with autoimmune thyroidopathies}

Yamaguchi et al. described a higher prevalence of DG in patients with uveitis associated with HTLV-1. ${ }^{52}$ Kawai et al. reported three patients with uveitis and arthritis related to HTLV- 1 and Graves' disease, suggesting that this thyroid disease was associated with the viral infection..$^{53}$

\section{HTLV-1 infection causing host immune derangement}

Oh et al. reported that the HTLV-1 Tax protein downregulates FOXP3, a gene which codifies a fundamental protein for the development and function of the T-cells. ${ }^{54}$ Mutations in FOXP3 results in alterations in subpopulations of regulator $\mathrm{T}$ lymphocytes, causing a primary immunodeficiency syndrome called IPEX (immunodysregulation, polyendocrinopathy, enteropathy, X-linked), presenting multiple endocrine alterations, including thyroiditis and insulin-dependent diabetes..$^{55}$

\section{CARBOHYDRATE DISORDERS}

\section{Type 1 diabetes mellitus}

Type 1 diabetes mellitus (T1DM) is a metabolic disorder caused by autoreactivity of T-cells resulting in destruction of beta cells in pancreatic islets. Viral infections are one of the mechanisms through which T1DM is triggered. Endogenous and exogenous retroviruses have been associated with the development of autoimmune diseases for its ability to integrate in the cellular genome. ${ }^{42}$

Concerning endogenous retrovirus, Conrad et al. have shown the presence of RNA sequences in the type $\mathrm{K}$ human endogenous retrovirus (HERV-K IDDMK1,222) in patients with T1DM raising the hypothesis that this virus would express a super-antigen able to trigger an immune T1DM..$^{56}$ However, Badenhoop et al. ${ }^{57}$ Jaeckel et al. ${ }^{58}$ and Muir et al. ${ }^{59}$ did not demonstrate differences between patients with T1DM and healthy controls concerning the expression of this retrovirus. More recently, a study has shown that the HERV-K18 retrovirus, through its $\mathrm{CD} 48$ region, participates in the pathogenesis of T1DM. ${ }^{60}$

As for exogenous retrovirus, Lagaye et al. detected the presence of sequences of the region gag of the HTLV-1 in patients with polyendocrinopathies. ${ }^{12}$ Nevertheless, the search for antibodies to HTLV-1 was negative in all patients. These findings lead the authors to speculate if the tested gag region would belong to only HTLV-1 or it would be a common site to other retrovirus, since other HTLV-1 genomic sites (pol e pX) were negative, not allowing to deduce a causal relationship between HTLV-1 infection and T1DM.

The only study about HTLV-1 and T1DM association was performed in Jamaica, describing a 17\% seroprevalence of HTLV-1 comparing to a $4 \%$ seroprevalence in the control group. ${ }^{11}$ The authors speculated if T1DM could be triggered by HTLV-1 infection. However, the small sample size and the fact that the control subjects were blood donors precluded data generalization. Other authors did not confirm these findings.

\section{GLUT-1 polymorphism}

The transportation of glucose between the several compartments of the organism is mediated through the glucose transporters (GLUT). ${ }^{61}$ Recently, it was shown that HTLV-1 use GLUT1 to infect T-CD4 (+) lymphocytes and polymorphisms in its gene could predispose some individuals to HAM/TSP, favoring the entrance of the virus into the cells, increasing its viral load and then its complications. ${ }^{62,63}$ However, a recent study was not able to find association between genetic susceptibility to HAM/TSP and g.22999g $>$ T, g.15339T $>$ C and c. -2841 A $>$ T polymorphisms of GLUT1 ${ }^{64}$ 


\section{ANTIDIURETIC HORMONE DISORDERS}

\section{Diabetes insipidus and inappropriate antidiuretic hormone secretion}

Only four articles, published in Japanese and cited by Adachi et al. ${ }^{9}$ reported $\mathrm{ADH}$ disorders in $\mathrm{HTLV}-1$ infected patients. ${ }^{65-68}$ Two of these articles reported five HTLV-1 infected patients with central diabetes insipidus ${ }^{65,66}$ probably by leukemic infiltration in the hypothalamus, thrombosis or infection in the central nervous system. ${ }^{9}$ As hypercalcemia can be expressed through nephrogenic diabetes insipidus, it is important to rule out this possibility when investigating diabetes insipidus in patients with ATLL. Other articles described two patients with the syndrome of inappropriate antidiuretic hormone secretion (SIADH). ${ }^{67,68}$

\section{RESEARCH PERSPECTIVES}

Figures 1 and 2 summarize the possible physiopathologic mechanisms of the HLV-1 associated endocrine disorders. Given the uncertainties of these associations, a theoretical discussion of research perspectives for the HTLV-1 and endocrine disorder associations is presented in order to stimulate works to fill the gaps of the current knowledge.

Figure 1: Mechanisms of hypercalcemia in HTLV-1 infection.

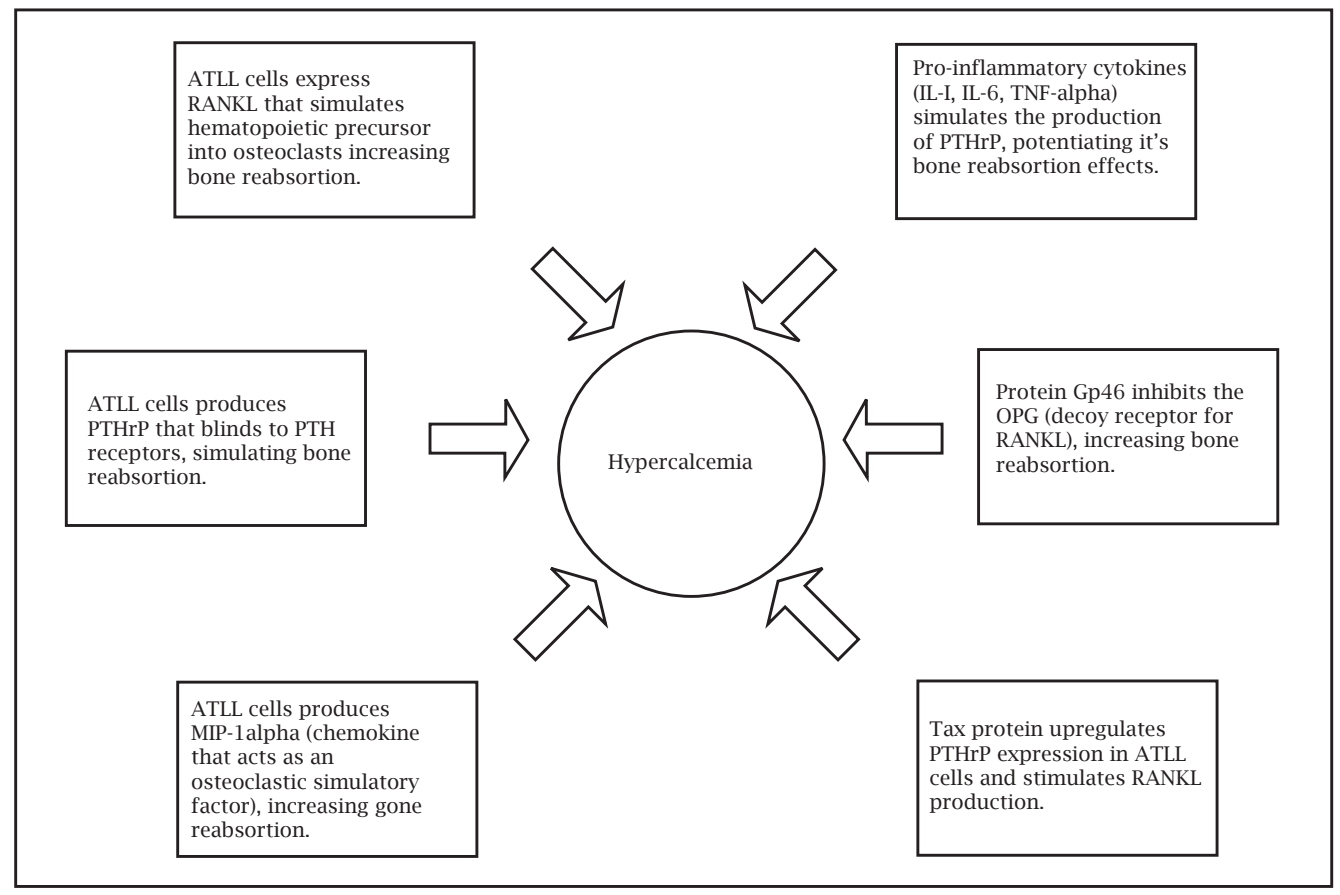

Figure 2: Endocrine disorders possibly associated with HTLV-1 infection.

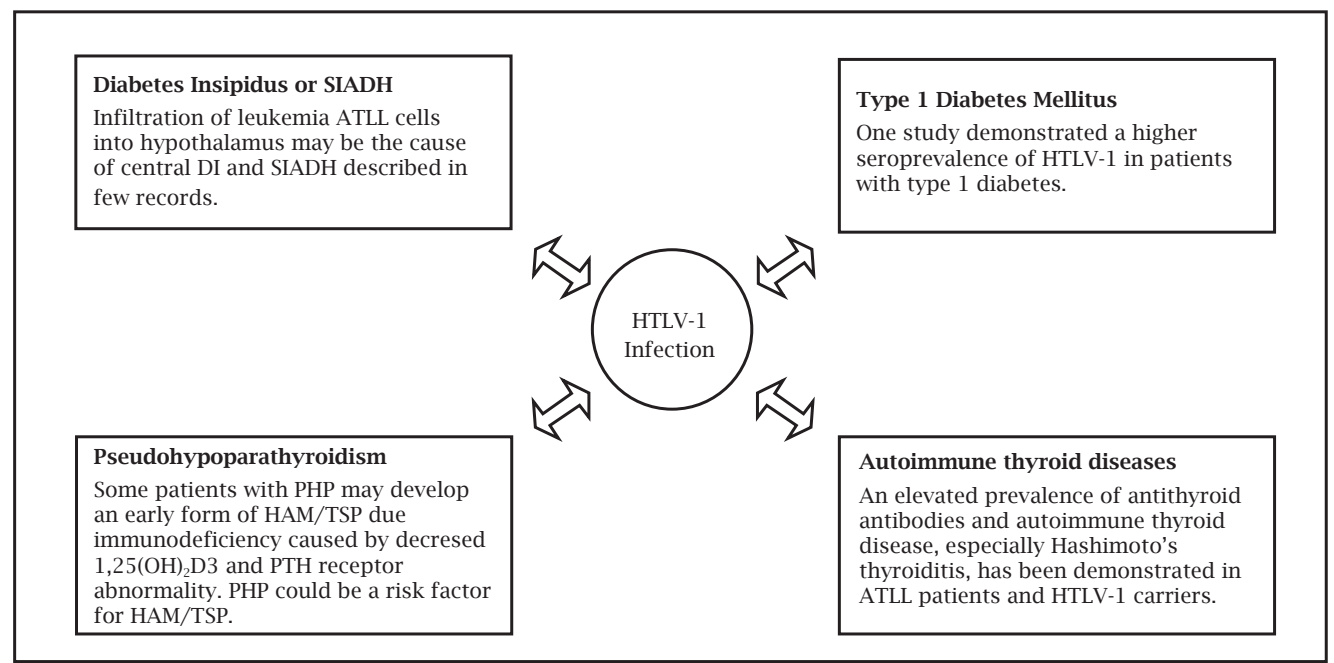

RANKL, Receptor activator for nuclear factor- $\kappa$ B Ligand; ATLL, adult T-cell leukemia lymphoma; PTHrP, parathyroid hormone related protein; OPG, osteoprotegerin; MIP-1alpha, macrophage inflammatory protein-alpha; IL, interleukin; TNF, tumor necrosis factor. 


\section{CALCIUM DISORDERS}

\section{Hypercalcemia and osteoporosis}

The identification of several mechanisms that lead to hypercalcemia in ATLL contributes to a better understanding of the metabolism of calcium and to studies aiming the application of new therapeutic agents to decrease the osteoclastic activity. For example, (I) osteoprotegerin (OPG): studies in mice with tumoral hypercalcemia showing a higher decrease in the serum calcium levels and an increase in the bone mass when these animals were treated with OPG when compared with the use of biphosphonates; ${ }^{69}$ (II) estrogens: since estrogen levels decreases with aging; and as the estradiol raise the expression of OPG, maybe its reposition could be one of the therapeutic alternatives in individuals with ATLL and hypercalcemia; ${ }^{70-72}$ (III) monoclonal antibody (denosumab) against RANKL: could block the osteoclastogenic actions mimicking the action of osteoprotegerin; ${ }^{73}$ (IV) monoclonal antibody against PTHrP: a study showed that this therapy is able to block the function of PTHrP and reduce the calcemia in mice; ${ }^{74}(\mathrm{~V})$ MIP-1alpha: the therapy with MIPlalpha can be other potential target to the treatment of hypercalcemia in the ATLL; ${ }^{30}$ and (VI) biphosphonates: besides its antirebsorptive effect, this class of drugs has been shown exert antitumoral properties, limiting the growth of ATLL cells. ${ }^{75}$

\section{PSEUDOHYPOPARATHYROIDISM AND PSEUDOPSEUDOHYPOPARATHYROIDISM}

The association between PHP and HTLV-1 is controversial and not proven. Thus more studies using more strict PHPIA and PPHP diagnostic criteria are necessary in order to: (I) study the activity of the Gs $\alpha$ in patients with small stature without HAM/TSP and in patients with normal stature and HAM/TSP; (II) study other endocrine manifestations associated with Gs $\alpha$ disorders; (III) verify the presence of hypovitaminosis D and its immunological collateral trigger of HAM/TSP; and (IV) evaluate the association between the precocious beginning of HAM/TSP in patients with PHP or PPHP who acquire HTLV-1 through blood transfusion.

\section{THYROID DISORDERS}

\section{Autoimmune thyroid diseases}

Although there is no study showing unequivocally a causal relationship between HTLV-1 infection and thyroid disorders, most of the studies support an association between them. ${ }^{41}$ It is possible that individuals with a determined genetic predisposition to thyroid diseases have a higher probability to develop them when infected by HTLV-1, as the viral infection by itself is not able to cause it. ${ }^{10}$ Similarities between the viral and host protein sequence can induce a cross reaction and an immune response against thyroid tissues or a viral infection can activate a clone of autoreactive T-cells that would induce a thyroid inflammation. It is still necessary more studies to understand the role of HTLV-1 in the development of autoimmune thyroid diseases.

\section{CARBOHYDRATE DISORDERS}

\section{Type 1 diabetes mellitus}

Only one article was found in the medical literature reporting a higher HTLV-1 seroprevalence in patients with T1DM comparing to healthy controls. ${ }^{11}$ Therefore, more studies are needed to confirm a possible role of the HTLV-1 infection as a trigger of T1DM or if the findings reported in a single study about the theme are attributed to a selection bias as the control group was assembled.

\section{GLUT-1 polymorphism}

Although Costa et al. did not demonstrate mutations in three polymorphisms of the GLUT1, it is not possible to rule out the possibility of other polymorphisms implicated in the genetic predisposition to HAM/TSP. ${ }^{64}$ Because of this, studies evaluating a larger number of polymorphisms are necessary to clarify this possible association.

\section{ANTIDIURETIC HORMONE DISORDERS}

\section{Diabetes insipidus and inappropriate antidiuretic hormone secretion}

Due to a small number of reports in the medical literature, more studies are necessary to prove a specific role of the HTLV-1 in the pathogenesis of these disorders or if these complications are only a result of a nervous system neoplasia or infectious aggression (ATLL immune suppression).

\section{CONCLUSIONS}

This review shows that the HTLV-1 endocrine associated diseases are mainly calcium disorders, which occurs in a subgroup of patients with ATLL. Why only some of the patients with HTLV-1/ATLL develop hypercalcemia remains unanswered. The few reports about thyroid, parathyroid disorder, $\mathrm{ADH}$ and T1DM are scanty to prove a causal association with HTLV-1 infection. The evidence for an association between endocrine disorders and HTLV-1 infection, in general, and in asymptomatic carriers is lacking. Given all the uncertainties, the endocrine expression of the HTLV-1 infection composes a promising research line for understanding the pathophysiology of this infection. 


\section{REFERENCES}

1. Schachter D, Cartier L, Borzutzky A. Osteoporosis in HTLV-Iassociated myelopathy/tropical spastic paraparesis (HAM/TSP) Bone. 2003; 33:192-6.

2. Bagossi P, Bander P, Bozóki B, Tözser J. Discovery and significance of new human T-lymphotropic viruses: HTLV-3 and HTLV-4. Expert Rev Anti Infect Ther.2009; 7:1235-49.

3. Santos FLN, Lima F WM. Epidemiologia, fisiopatogenia e diagnóstico laboratorial da infecção pelo HTLV - I. J Bras Patol Med Lab. 2005; 2:105-16.

4. Nakauchi CM, Maruyama K, Kanzaki LI et al.Prevalence of HTLV-I antibody among two distinct ethnic groups inhabiting the Amazon region of Brazil. Rev Inst Med Trop. 1992; 34:323-38.

5. Ishak R, Vallinoto ACR, Azevedo VN, Ishak MOG. Epidemiological aspects of retrovirus (HTLV) infection among Indian populations in the Amazon Region of Brazil. Cad Saúde Pública (Rio de Janeiro). 2003; 19:901-14.

6. Vallinoto ACR, Pontes GS, Lopes IGL et al. Identification og human t-cell lymphotropic vírus infection in a semi-isolated AfroBrazilian quilombo located in the Marajó Island (Pará, Brazil). Mem Inst Oswaldo Cruz. 2006; 10:103-105.

7. Mota A, Nunes C, Melo A et al. A case-control study of HTLVinfection among blood donors in Salvador, Bahia, Brazil - associated risk factors and trend towards declining prevalence. Rev Bras Hematol Hemoter. 2006; 28:120-6.

8. Moxoto I, Boa-Sorte N, Nunes C et al. Perfil sociodemográfico, epidemiológico e comportamental de mulheres infectadas pelo HTLV-I em Salvador-Bahia, uma área endêmica para o HTLV. Rev Soc Bras Med Trop. 2007; 40:37-41.

9. Adachi M, Shiomura T, Shimada $\mathrm{H}$ et al. Adult T-cell leukaemia with various abnormalities in endocrine and metabolic systems. Br J Haematol. 1994; 87:853-55.

10. Akamine H, Takasu N, Komiya I et al. Association of HTLV-1 with autoimmune thyroiditis in patients with adult T-cell leukaemia (ATL) and in HTLV-1 carriers. Clin Endocrinol. 1996; 45:461-6.

11. Smikle MF, Wright-Pascoe R, Barton EN et al. Autoantibodies, human T lymphotropic virus type I and type 1 diabetes mellitus in Jamaicans. West Indian Med J. 2002; 5:153-6.

12. Machigashira N, Yoshida Y, Wang S, Osame M. HTLV-I-associated myelopathy/tropical spastic paraparesis with pseudohypoparathyroidism. Neurology. 2001; 56:104-6.

13. Kiyokawa T, Yamaguchi K, Takeya M et al. Hypercalcemia and osteoclast proliferation in adult T-cell leukemia. Cancer.1987; 59:1187-91.

14. Sagara Y, Inoue Y, Sagara Y, Kashiwagi S. Involvement of molecular mimicry between human T-cell leukemia virus type 1 gp46 and osteoprotegerin in induction of hypercalcemia. Cancer Sci. 2009; 100:490-6.

15. Nicot C. Current views in HTLV-I-associated adult T-cell leukemia/lymphoma. Am J Hematol. 2005; 75:232-9.

16. Edwards CM, Edwards SJE, Bhumbra R, Chowdhury TA. Severe refractory hypercalcaemia in HTLV-1 infection. J R Soc Med. 2003; 96:126-7.

17. Nadella MVP, Shu ST, Dirksen WP et al. Expression of parathyroid hormone-related protein during immortalization of human peripheral blood mononuclear cells by HTLV-I: implications for transformation. Retrovirology. 2008; 5:46-58.

18. Nosaka K, Miyamoto T, Sakai T et al. Mechanism of hypercalcemia in adult T-cell leukemia: overexpression of receptor activator of nuclear factor kappa B ligand on adult T-cell leukemia cells. Blood. 2002; 99:634-40.

19. Hagler K, Lynch J. Paraneoplastic manifestations of lymphoma. Clin Lymphoma. 2004; 5:29-36.
20. Lyell V, Khatamzas E, Allain T. Severe hypercalcemia and lymphoma in a HTLV-I positive Jamaican woman: a case report. J Med Case Reports. 2007; 1:56.

21. Shoback D. Update in osteoporosis and metabolic bone disorders. J Clin Endocrinol Metab. 2007; 92:747-53.

22. Rogers A, Eastell R. Circulating osteoprotegerin and receptor activator for nuclear factor $\mathrm{kB}$ ligand: clinical utility in metabolic bone disease assessment. J Clin Endocrinol Metab. 2005; 90:6233-31.

23. Simonet WS, Lacey DL, Dunstan CR et al. Osteoprotegerin: a novel secreted protein involved in the regulation of bone density. Cell. 1997; 89:309-319.

24. Bucay N, Sarosi I, Dunstan CR et al. Osteoprotegerin-deficient mice develop early onset osteoporosis and arterial calcification. Genes Dev. 1998; 12:1260-8.

25. Fukumoto S, Matsumoto T, Ikeda K et al. Clinical evaluation of calcium metabolism in adult T-cell leukemia/lymphoma. Arch Intern Med. 1988; 148:921-5.

26. Fukumoto S, Matsumoto T, Watanabe T et al. Secretion of parathyroid hormone-like activity from human T-cell lymphotropic virus type I-infected lymphocytes. Cancer Res.1989; 49:3849-52.

27. Motokura T, Fukumoto S, Takahashi S et al. Expression of parathyroid hormone-related protein in a human T cell lymphotrophic virus type I-infected T cell line. Biochem Biophys Res Commun. 1988; 154:1182-8.

28. Watanabe T, Yamaguchi K, Takatsuki K et al. Constitutive expression of parathyroid hormone-related protein gene in human T cell leukemia virus type $1(\mathrm{HTLV}-1)$ carriers and adult T cell leukemia patients that can be trans-activated by HTLV-1 tax gene. J Exp Med. 1990; 172:759-65.

29. Richard V, Laimore MD, Green PL et al. Severe combined immnudeficiency/beige mouse model of adult T-cell lymphoma independent of human T-cell lymphotropic virus type-1 Tax expression. Am J Pathol. 2001; 158:2219-28.

30. Okada Y, Tsukada J, Nakano K et al. Macrophage inflammatory protein-1alpha induces hypercalcemia in adult T-cell leukemia. J Bone Miner Res. 2004; 19:1105-11.

31. Fu Q, Jilka RL, Manolagas SC, O'Brien CA. Parathyroid hormone stimulates receptor activator of NFkB ligand and inhibited osteoprotegerin expression via protein kinase A activation of cAMP-response element-binding protein. J Biol Chem. 2002; 277:48868-75.

32. Gao L, Deng H, Zhao H et al.HTLV-1 Tax transgenic mice develop spontaneous osteolytic bone metatastases prevented by osteoclastic inhibition. Blood. 2005; 106:4294-302.

33. Zhou Z, Apte SS, Soinemen R et al. Impaired endochondral ossification and angiogenesis in mice deficient in membrane-type matrix metalloproteinase 1. Proc Natl Acad Sci (USA). 2000; 97:4052-7.

34. Root AW, Diamond Jr FB. Disorders of mineral homeostasis in the newborn, infant, child and adolescents. In: Pediatric Endocrinology, edn 3, pp 686-768. Philadelphia: Saunders, 2008.

35. Yoshida Y, Sakamoto Y, Yoshime A et al. Three cases of juvenile onset HTLV-I-associated myeolopathy with pseudohypoparathyroidism. J Neurol Sci. 1993; 111:145-9

36. Yoshida Y, Machigashira N, Wang S, Osame M. A patient with acute-onset HAM/TSP after blood transfusion complicated with pseudopseudohypoparathyroidism. Intern Med. 2002; 41:899-900.

37. Fritzen R. HTLV-I associated myelopathy/tropical spastic paraparesis with pseudohypoparathyroidism. Neurology. 2001; 57:1349-50.

38. Prummel MF, Strieder T, Wiersinga WM. The environment and autoimmune thyroid diseases. Eur J Endocrinol. 2004; 150:605-18.

39. Tomer Y, Huber A. The etiology of autoimmune thyroid disease: A story of genes and environment. J Autoimmun. 2009; 32:231-39. 
40. Prummel MF, Laurberg P. Interferon-alpha and autoimmune thyroid disease. Thyroid. 2003; 13:547-551.

41. Harii N, Lewis CJ, Vasko V et al. Thyrocytes express a functional toll-like receptor 3: overexpression can be induced by viral infection and reversed by phenylmethimazole and is associated with Hashimoto's autoimmune thyroiditis. Mol Endocrinol. 2005; 19:1231-1250.

42. Lagaye S, Vexiau P, Morozov V et al. Detection of HTLV-I gag related sequences in leukocyte DNA from patients with polyendocrinopathies (Basedow-Graves' disease and insulin-dependent diabetes). C R Acad Sci III. 1991; 312:309-15.

43. Kawai H, Inui T, Kashiwagi S et al. HTLV-1 infection in patients with autoimmune thyroiditis (Hashimoto's thyroiditis). J Med Virol. 1992; 38:138-41.

44. Mizokami T, Okamura K, Ikenoue $\mathrm{H}$ et al. High prevalence of human T-lymphotropic vitus type I carriers in patients with antithyroid antibodies. Thyroid. 1994; 4:415-9.

45. Mine H, Kawai H, Yokoi K, Akaike M, Saito S. High frequencies of human T lymphotropic virus type 1 (HTLV-1) proviral DNA in blood donors with anti-thyroid antibodies. J Molecular Med. 1996; 74:471-7.

46. Kawai $\mathrm{H}$, Mitsui T, Yokoi K et al. Demonstration of viral protein of HTLV-I and its messenger RNA in thyroid tissue of HTLV-I carriers with Hashimoto's thyroiditis. J Clin Exp Med (Tokyo). 1994; 169:965-6.

47. Kawai H, Mitsui T, Yokoi K et al. Evidence of HTLV-I in thyroid tissue in an HTLV-I carrier with Hashimoto's thyroiditis. J Mol Med. 1996; 74:275-8.

48. Filho RAC, Vaisman M, Vilar EAG, Fonseca EC. Expressão das proteínas p19(gag) e gp 21 (env) do HTLV-I no tecido tireoidiano de pacientes com doença autoimune da tireóide e no tecido tireoidiano normal. Arq Bras Endocrinol Metab. 2000; 44:417-424.

49. Matsuda T, Tomita M, Uchihara JN et al.Human T cell leukemia virus type I-infected patients with Hashimoto's thyreoiditis and Grave's disease. J Clin Endocrinol Metab. 2005; 90:5704-5710.

50. Tomer Y, Greenberg DA, Barbesino G, Concepcion E, Davies TF. CTLA-4 and not CD28 is a susceptibility gene for thyroid autoantibody production. J Clin Endocrinol Metab. 2001; 86:1687-93.

51. Tomoyose T, Komiya I, Takara $\mathrm{M}$ et al. Cytotoxic T-lymphotrophic virus-1 infection: their associations with Hashimoto's thyroiditis in Japanese patients. Thyroid. 2002; 12:673-7.

52. Yamaguchi K, Mochizuki M, Watanabe T et al. Human T lymphotropic virus type 1 uveitis after Graves disease. Br. J Ophthalmol. 1994; 78:163-6.

53. Kawai H, Yokoi K, Akaike M et al. Graves disease in HTLV-I carriers. J Mol Med. 1995; 73:85-8.

54. Oh U, Grant C, Griffith C et al. Reduced Foxp3 protein expression is associated with inflammatory disease during human t lymphotropic virus type 1 Infection. J Infect Dis. 2006; 193:1557-66.

55. Marabelle A, Meyer M, Demeocq F, Lachaux A. From Ipex to foxp3: a new contribution of pediatrics to the understanding of the immune system. Arch Pediatr. 2008; 15:55-63.

56. Conrad B, Weissmahr RN, Boni J et al. A human endogenous retroviral superantigen as candidate autoimmune in type 1 diabetes. Cell. 1997; 90:303-313.

57. Badenhoop K, Donner H, Neumann J et al. IDDM patients neither show humoral reactivities against endogenous retroviral envelop protein nor do they differ in retroviral mRNA expression from healthy relatives or normal individuals. Diabetes. 1999; 48:215-8.

58. Jaeckel E, Heringlake S, Berger D et al. No evidence for association between IDDMK1,222 a novel isolated retrovirus and IDDM. Diabetes. 1999; 48:200-14.
59. Muir A, Ruan Q, Marron MP, She J. The IDDDMK1,222 retrovirus is not detectable in either mRNA or genomic DNA from patients with type 1 diabetes. Diabetes. 1999; 48:219-22.

60. Marguerat S, Yang WYS, Todd JA, Conrad B. Association of human endogenous retrovirus K-18 polymorphisms with type 1 diabetes. Diabetes. 2004; 53:852-54.

61. Swainson L, Kinet S, Manel $\mathrm{N}$ et al. Glucose transporter 1 expression identifies a population of cycling CD4+ CD8+ human thymocytes with high CXCR4-induced chemotaxis. PNAS. 2005; 102:12867-72.

62. Manel N, Kim NS, Kinet N et al. The ubiquitous glucose transporter GLUT-1 is a receptor for HTLV. Cell. 2003; 115:449-59.

63. Coskun AK, Sutton RE. Expression of glucose transporter 1 confers susceptibility to human T-cell leukemia virus envelopemediated fusion. J Virol. 2005; 79:4150-8.

64. Costa GC, Azevedo R, Gadelha SR et al. Polymorphisms at GLUT1 gene are not associated with the development of TSP/ HAM in Brazilian HTLV-1 infected individuals and the discovery of a new polymorphism at GLUT1 gene. J Med Virol. 2009; 81:552-7.

65. Katsuno M, Uchida E, Goto K et al.Adult T-cell leukaemia presenting with pancytopenia followed by diabetes insipidus. Rinsho Ketsueki. 1987; 28:730-37.

66. Ishii M, Kubota K, Matsuoka Y, Yamaguchi K, Takatsuki K. Chronic adult T-cell leukemia with T4 and T8 positive leukaemic cells associated with central diabetes insipidus. Rinsho Ketsueki. 1987; 28:578-82.

67. Kawasaki C, Hayashi S, Shibuya T et al. Syndrome of inappropriate secretion of antidiuretic hormone in the central nervous system involvement of adult T-cell leukaemia. Rinsho Ketsueki. 1988; 29:1482-87.

68. Teshima T, Nakahara Y, Hirata Y et al. Adult T-cell leukaemia with brain mass complicated with inappropriate secretion of ADH. Rinsho Ketsueki. 1988; 29:2307-11.

69. Morony S, Warmington K, Adamu S et al. The inhibition of RANKL causes supression of bone resorption and hypercalcemia compared with biphosphonates in two models of humoral hypercalcemia of malignancy. Endocrinology. 2005; 146:3235-43.

70. Mazziotti G, Amato G, Sorvillo F et al. Increased serum osteoprotegerin values in long-lived subjects: different effects of inflammation and bone metabolism. Eu J Endocrinol. 2006; 154:373-7.

71. Szulc P, Hofbauer LC, Heufelder AE, Roth S, Delmas PD. Osteoprotegerin serum levels in men: correlation with age, estrogen and testosterone status. J Clin Endocrinol Metab. 2001; 86:3162-65.

72. Bekker PJ, Holloway D, Nakanishi A et al. The effect of a single dose of osteoprotegerin in postmenopausal women. J Bone Miner Res. 2001; 16:348-60.

73. McClung MR, Lewiecki EM, Cohen SB et al. AMG 162 Bone Loss Study Group. Denosumab in postmenopausal women with low bone mineral density. N Engl J Med. 2006; 354:821-31.

74. Onuma E, Sato K, Saito H et al. Generation of a humanized monoclonal antibody against human parathyroid hormone-related protein and its efficacy against humoral hypercalcemia of malignancy. Anticancer Res. 2004; 24:2665-74.

75. Ishikawa C, Matsuta T, Okudaira $\mathrm{T}$ et al. Biphosphonate incadronate inhibits growth of human T-cell leukemia vírus type 1-infected T-cell lines and primary adult T-cell leukemia cells by interfering with the mevalonate pathway. Br J Haematol. 2007; 136:424-32. 